\title{
Pediatric Cardiology and Social Engineering
}

\author{
Ra-id Abdulla
}

Published online: 10 September 2014

(C) Springer Science+Business Media New York 2014

Over the past several centuries, free-market capitalism has been a constant feature of developed countries, leading to industrial, economic, and scientific prosperity of its nations. The introduction of governing laws in these countries to ensure fairness and equity in opportunities within a free-market system were essential in maintaining its continuity through safeguarding sustainability. Healthcare delivery in developed countries enjoyed success in free-market environments, perhaps due to the competitive spirit such an environment produces coupled with legislative regulations to ensure safety as well as equity of delivery. These legislative measures were socially and politically driven in attempts to impose social engineering aimed to produce safe and equitable delivery of health care. It is true that the term "social engineering" carries a negative connotation in the western world, particularly in the United States, where wide-scale and drastic reshaping of society is viewed as a feature of authoritarian governments, particularly communist regimes. Nevertheless, social engineering of healthcare programs has become an integral part of healthcare in all developed countries, ensuring effective and unhindered health care to the communities it serves.

Healthcare delivery in the field of pediatrics is particularly vulnerable to unchecked free market. Unlike other citizens, children do not vote and, as such, cannot form an interest group advocating for their rights or exercise punitive actions through the ballot boxes. Furthermore, children are parented and represented by young individuals with limited financial capabilities and are typically

R. Abdulla $(\bowtie)$

Department of Pediatric Cardiology, Rush University Medical Center, Chicago, IL 60612, USA

e-mail: ra-id_abdulla@rush.edu inexperienced in navigating the hurdles they may encounter in facilitating healthcare for their children. In addition, their roles as advocates only last a limited time, as their young children will inevitably grow and parents lose the incentive to promote pediatric healthcare interests. In the United States, healthcare systems are expected to generate income, or at least sustain financial viability through billings generated by physicians and hospitals. Under such conditions, pediatrics remains a losing enterprise. Care for children's health is costly and revenues paid by insurance companies and parents are limited, rendering the need for legislative intervention more compelling to secure its continuity as a minimum and advancement as a goal.

Pediatric cardiology, a small fraction of the field of pediatrics, is even more vulnerable to the whims of free market. Free market is necessary as an environment to produce competition leading to the refinement of science and clinical practice in this field. However, legislative intervention as a social engineering tool is much needed to ensure the dedication of resources to produce growth in basic science and translational research on one hand and equity in delivery to all members of the society on the other. Allowing free market to create a competitive field where survival is granted to those who can achieve most can certainly boost the science and practice of pediatric cardiology. This has been shown in studies where research output was found to correlate positively with higher gross domestic product (GDP), lower national levels of corruption, higher standard of education, urbanization, and presence of national centers of excellence [1], all features distinctly superior in societies governed by free market. The United States and other Western countries, as well as Japan, took the lead in research productivity in this study, all countries where free market produces high GDP and other features which enable higher research output. These 
findings are not surprising as it is evident from every other area of scientific development where competition clearly produces advances in product. On the other hand, delivery of care within each nation of those who lead research and development of the science of pediatric cardiology is clearly not equal. Centers of excellence, where large number of patients are cared for, secure more research funding and produce larger number of articles in this field. Smaller centers, which constitute the majority of centers and care in populations around the world, lag behind in research productivity as well as care delivery, as shown in numerous publications where larger centers enjoy smaller morbidity and mortality in children with heart diseases [2, 4]. Inequity in care delivery has been tackled in Sweden, which enjoys a strong free-market economy; however, like many European countries, medical care in Sweden enjoys protection and strength through social engineering measures. Until recently, Sweden had four medical centers providing advanced pediatric cardiac care. Two of these centers enjoyed good results, the other two centers lagged behind. Governmental intervention to improve outcome led to the closure of the two centers with lesser results and diversion of patients for care in the two centers with better statistical outcomes for children with heart diseases [3]. The Swedish experience supports the notion that free market may indeed provide positive attributes to the development of medical care in pediatric cardiology; however, without intervention through social engineering, the outcome is uneven.

Intervention to provide advanced and equitable care in pediatric cardiology is not limited in its necessity to tempering and guiding the potential unfairness of free market. It also assumes a crucial role in providing highly specialized care to parts of the world where such healthcare delivery is otherwise impossible. The majority of world's population lives in countries where poverty and instability caused by human malevolence hinder the development of adequate, let alone advanced medical care. Poverty and misuse of resources play an important role in poor healthcare delivery in many such countries; however, inane squabbling by political factions driven by power and fortune hoarders are the leading causes of poor healthcare delivery in the overwhelming majority of developing countries. In such regions of the world, pediatric cardiology and cardiac surgery are mostly limited to simpler procedures performed at older age to a limited number of the population. In such cases, advanced health care can only be provided through global social engineering carried out by global and/or charitable organizations willing to transplant such care to regions where it could never, on its own, thrive or even exist.

Medical professionals in pediatric cardiology and cardiovascular surgery, like many other high-end specialties, participate considerably in charitable and global efforts. Physicians, surgeons, nurses, and technicians in this field witness the stark difference in what can be done at medical centers in developed countries where they practice versus what is available in underdeveloped healthcare systems in impoverished regions of the world. The enormous gap in medical care between the have and have not frequently leads to frustration with the inequality of care on one hand and fanatical dedication toward equalizing this canyon gap through addiction to their cause. This infectious spirit, which spreads rampantly amongst those who participate in medical mission work, enables high-end medical care delivery to many parts of the world. A particular type of medical mission provides long-lasting impact; this is when an effort is made to recruit and cultivate local expertise to leave behind self-sustaining centers capable of independent growth.

Over the past two decades, I had the opportunity to be part of such missions through the Palestine Children's Relief Fund (PCRF), an American charitable organization based in Kent, Ohio, as it established the first pediatric cardiology and cardiac surgery program in East Jerusalem, eventually resulting in a self-sufficient program for cardiac surgery at Al-Makassed Hospital. Through the help of many notable pediatric cardiologists and surgeons from Europe and the United States, PCRF recently initiated a similar program in Gaza. The most recent calamities in Gaza halted all efforts in developing such a program, and the utter devastation to the local infrastructure will make it much harder to resume building a pediatric cardiac surgery program at the European Hospital in Gaza.

Intervention through legislation and governmental funding in providing needed medical care for a subset of population within a nation is frequently practiced in developed and developing countries. Is it possible to imagine that the same can be practiced for regions or countries of the world where grave injustice, military conflict, or stark poverty prohibits any hope of such medical care being established without social engineering? The United Nations, through its multitude of agencies, is limited by design in what it can provide when military conflict is the cause of suffering. These responsibilities frequently rest on the shoulders of powerful nations such as the United States and the European Union, but unfortunately despite their military might assume an impotent role and are content with lavishing advice or chastisement in dealing with many of these conflicts. Medical professionals in every corner of the world must stand firm on equal and unhindered healthcare delivery to each and every member of the human race and must work together to equalize heath care delivery on a global scale. Medical professionals must transfer their experience in the trenches to advocating a 
global initiative to provide a uniform medical care delivery worldwide and impose their will on hesitating and unwilling governments and global organizations. Medical professionals have surrendered leadership of structuring healthcare delivery to governments and politicians; it is odd that those who make it possible to have health care do not lead the way in how this care should be delivered. Medical care professionals are known to group and organize to promote research and clinical practice, but not to structure and run the healthcare system they make possible. Is it time to take on the responsibility of leading global healthcare delivery? In my opinion, the answer is a resounding "Yes"!

\section{References}

1. Bräutigam M, Kempny A, Radke R et al (2014) Spatial and Temporal Overview of Research in Pediatric and Congenital Cardiology: trends and Global Challenges. Pediatr Cardiol 35:1007-1019. doi:10.1007/s00246-014-0889-3

2. Kalfa D, Chai P, Bacha E (2014) Surgical volume-to-outcome relationship and monitoring of technical performance in pediatric cardiac surgery. Pediatr Cardiol 35(6):899-905. doi:10.1007/ s00246-014-0938-y. Epub 2014 Jun 4

3. Lundstrom NR, Berggren H, Bjorkhem G et al (2000) Centralization of pediatric heart surgery in Sweden. Pediatr Cardiol 21:353-357

4. Pasquali SK, Li JS, Burstein DS et al (2012) Association of center volume with mortality and complications in pediatric heart surgery. Pediatrics 129:e370-e376 